\author{
Bożena CZARNECKA \\ ORCID: 0000-0002-8901-2061 \\ Uniwersytet Wrocławski
}

\title{
Een schrijver verdwaald in het massamedialand
}

\begin{abstract}
The mass media are a prominent actor in the current debate on literature. In many ways, they contribute to defining its terms and settings, including what is said, whose voice is deemed valid/legitimate, and how it is all done/expressed. The mass media no longer merely mediate; rather, they produce views on and assessments of writers and their work. In his book De literatuur draait door. De schrijver in het mediatijdperk (2019), Sander Bax discusses selected cases of the media presence of well-known Dutch authors and their books to offer an insightful and accurate exploration of the ways in which the mass media influence the debate on literature and literature itself.
\end{abstract}

Keywords: mass media, mediatisation of literature, media convergence, Sander Bax.

De literatuur van de eenentwintigste eeuw blijkt steeds meer beïnvloed door de massamedia ${ }^{1}$ en de regels daarvan, die niet helemaal overlappen met de klassieke twintigste-eeuwse (modernistische en autonomistische) opvattingen over literatuur, waarin de nadruk wordt gelegd op eigenschappen als fictionaliteit, opvallend en niet-alledaags taalgebruik of meerduidigheid. ${ }^{2}$ Maar als we literatuur wat breder beschouwen als onderdeel van een communicatief systeem, als specifiek medium dat dient om bepaalde ideeën over te dragen (en erbij te bemiddelen) en als zodanig op een natuurlijke wijze met andere media convergeert, dan hoeft die groeiende invloed van de massamedia op de literatuur in principe niet te verbazen.

Aan dit op zich fascinerende en complexe fenomeen van de mediatisering van de literatuur is het boek De literatuur draait door. ${ }^{3}$ De schrijver in het media-

${ }^{1}$ Hieronder vallen radio, tv, dag- en weekbladen, sociale media.

${ }^{2}$ Er is geen eenduidige en algemeen geldige omschrijving van wat literatuur is. Alle bestaande definities lijken af te hangen van de historische en ideologische contexten waarin ze ontworpen zijn.

3 De hoofdtitel verwijst naar De wereld draait door, een van de bekendste Nederlandse TVpraatprogramma's (2005-2020), vaak met schrijvers te gast, waarmee het verband tussen literatuur en massamedia benadrukt wordt. Tegelijk schijnt dit een subtiele (en optimistische?) indicatie te zijn 
tijdperk (2019) van Sander $\mathrm{Bax}^{4}$ gewijd, door de auteur zelf gekarakteriseerd als "reeks dieptepeilingen in de literaire cultuur van de eenentwintigste eeuw" (317). ${ }^{5}$ Bax' verkenningen betreffen een cultuur die steeds meer wordt bepaald door mediawetten, wat indirect leidt tot het herformuleren van de sociale functie van de schrijver. De auteur richt zich vooral op de Nederlandstalige literatuur in het tijdperk van de massamedia. Hij onderzoekt hoe die massamedia inwerken op schrijvers en de boeken die zij schrijven, zowel op de inhoud als ook de vorm ervan. Daarnaast probeert Bax erachter te komen hoe het publieke mediadebat over de literatuur verloopt. Hij gaat ervan uit dat dat debat in aanzienlijke mate beïnvloed wordt door media logics. Daaronder verstaat hij een aantal "discursieve" wetten, waarmee allerlei "ongeschreven regels" worden bedoeld waaraan iedereen zich moet houden om "succesvol over te komen" (17). Ze zouden ook verantwoordelijk zijn voor drie opmerkelijke ontwikkelingen in de hedendaagse literatuur, vanwege hun invloed op de schrijvers en datgene wat ze schrijven. ${ }^{6}$

De eerste van die drie tendensen betreft het belang van het fenomeen 'succes' in de contemporaine literaire mediacultuur. De tweede ontwikkeling wordt door Bax angeduid als "de fascinatie van de media voor het 'echte', het 'intieme' en het 'waargebeurde" (18), wat tot de groeiende productie van allerlei soorten (semi-)autobiografische teksten en non-fictie genres zou leiden. De derde ontwikkeling slaat op "het spreken over actualiteit en politiek", wat voortvloeit uit "het gepolariseerde politieke debat" (19) dat gestimuleerd wordt door de media.

Het door Bax uitgevoerde onderzoek is duidelijk geënt op het theoretisch werk van Pierre Bourdieu. Door zijn concept van het culturele veld toe te passen kan hij de sociale dimensie van de recente literatuurprocessen beter naar voren laten komen. Het literaire en het mediaveld, nog niet zo lang geleden in principe aparte systemen van relaties en instituties, met eigen regels, raken tegenwoordig

over de toekomst van de literatuur die ondanks alles blijft voortbestaan, maar - niet uitgesloten onder een andere gedaante die we nog niet (kunnen) kennen.

${ }^{4}$ Sander Bax (1977) is verbonden aan de Universiteit van Tilburg, waar hij werkt als universitair hoofddocent cultuurgeschiedenis, literatuurwetenschap en vakdidactiek Nederlands. Met de problematiek van de wisselwerking tussen literatuur en media ging hij zich bezighouden mede dankzij zijn onderzoek naar "het mediafenomeen Harry Mulisch" (Ruyters 2019), wat in het boek De Mulisch mythe. Harry Mulisch: schrijver, intellectueel, icoon (2015) resulteerde.

5 Citaten in de tekst, tenzij anders vermeld, zijn ontleend aan het boek De literatuur draait door.

${ }^{6}$ In de mediawetenschappen wordt media logic algemeen omschreven als "de organisatorische, technologische en esthetische determinanten van de manier waarop verschillende media functioneren, inclusief formele en informele regels" (Loisen \& Joye 418). Benadrukt wordt dat diverse media hun eigen specifieke logics hebben, maar tegelijk dat er ook een paar eigenschappen zijn die ze met elkaar delen: "McQuail (2010, p. 563) spreekt over (vormelijke en inhoudelijke) elementen zoals personaliseren, sensatie, conflict, drama en hoog tempo als componenten die een brede aantrekkingskracht hebben en dus de aandacht van het publiek bevorderen" (Loisen \& Joye 418). Min of meer komt dit overeen met de mediawetten die volgens Bax van invloed zijn op literatuur. 
steeds meer met elkaar vervlochten. Het feit dat de productie, promotie of receptie van literatuur steeds vaker buiten het traditionele literaire veld gebeurt, en wel binnen het mediaveld, kan daar een bewijs voor zijn.

De literatuur draait door is gekenmerkt door de driedelige opbouw. Het boek opent met een theoretische expositie van het hoofdonderwerp ("De literatuur draait door", 13-58) waar Bax precies uitlegt wat hij met zijn onderzoek beoogt. De doorwerking van het thema gebeurt in drie daaropvolgende delen waarvan elk gewijd is aan een van drie bovengenoemde discursieve regels. Het slotdeel ("De literatuur draait door (reprise)", 297-324) bevat enkele recapitulaties en conclusies over de status van de "gemediatiseerde" literatuur en schrijver als mediafiguur in de eerste twee decennia van de eenentwintigste eeuw. Verder is het boek voorzien van een omvangrijke noten- en literatuurlijst alsook een namenregister.

De al genoemde discursieve regels zijn als het ware assen waar Bax' verhaal over literatuur in het massamediatijdperk om draait. Ze worden rijkelijk geillustreerd met bekende literaire werken die verduidelijken hoe die regels in de literaire praktijk worden toegepast. ${ }^{7}$ In Deel 1 ("De schrijver en het succes", 61-132) staat het behalen van literair succes centraal, wat te herleiden is tot literatuur schrijven die goed verkoopt en in de smaak valt bij het doorsnee publiek. ${ }^{8}$ Dat wordt gemeten door hoge verkoopcijfers, erkende literaire prijzen of vertalingen in vreemde talen. Voorbeelden voor literair succes die in dit boekdeel nader worden besproken, zijn de bestsellers Terug naar de kust (2003) van Saskia Noort, Komt een vrouw bij de dokter (2003) van Kluun en Het diner (2013) van Herman Koch.

In Deel 2 ("Het privéleven van de schrijver", 133-209) wordt uitgeplozen waar de groeiende neiging onder schrijvers om over het persoonlijke leven te schrijven, mogelijk vandaan komt. Deze trend gaat vergezeld met o.a. een "verlangen naar de authentieke en intieme verhalen van celebrityschrijvers" (198) dat onder de lezers waargenomen wordt. Dat zou volgens Bax (onder zeker voorbehoud) een aanvaardbare verklaring kunnen zijn voor het groeiend aantal literaire werken met verwerkte autobiografische gegevens. Zijn bevindingen in dit deel worden gebaseerd op analyses van boeken als Logboek van een onbarmhartig jaar (2011) van Connie Palmen, Bad Boy (2013) van Abdelkader Benali, De vrouw die de honden eten gaf (2014) van Kristien Hemmerechts, Brieven uit Genua (2016) van Leonard Pfeijffer en Tonio. Een requiemroman (2011) van A.F.Th. van der Heijden. Vooral het laatstgenoemde boek zou volgens Bax de

7 Wat de selectie van teksten betreft, valt het op dat de literaire productie uit de periode 20112016 sterk oververtegenwoordigd is, hoewel het boek de wisselwerking tussen literatuur en mediacultuur in een langere periode (grofweg twee decennia) behandelt.

8 Dergelijk succes wordt onder meer gegarandeerd door overname van motieven of verhaaltechnieken en - strategieën, typisch voor de genres die vroeger tot lage literatuur gerekend werden. 
gespannen verhouding tussen fictie en werkelijkheid ${ }^{9}$ goed weergeven, wat zich onder meer uit in het toelaten van twee tegengestelde leeswijzen, de fictionele en realistische. Andere interessante onderwerpen die hier aan bod komen, zijn de relatie tussen literatuur en roddel (definitie van roddelen, roddel als communicatievorm, 188-189) of het fenomeen van paparazzi (198).

Deel 3 ("De schrijver en de politiek", 211-296) gaat over engagement en literair populisme. Een schrijver die zijn mening over bepaalde politieke, economische of morele kwesties publiekelijk wil delen, moet zijn standpunten in het debat scherp, zelfverzekerd en liefst zo controversieel mogelijk formuleren. Want in de massamedia, die toch zo graag antagoniseren, worden "auteurs met uitgesproken en expliciete politieke opvattingen" vanzelfsprekend bevoorrecht op "auteurs die problematiseren en compliceren" (320). Ter illustratie daarvan worden VSV (2012) van Leon de Winter en La Superba (2013) van Ilja Leonard Pfeijffer geanalyseerd.

Bax' boek levert overtuigend bewijs dat de massamedia zich al sinds enige tijd niet meer beperken tot slechts literatuur presenteren, maar ook zelf literatuur enigszins mede proberen te ontwerpen of construeren. Het verschijnsel zelf is herkenbaar, maar het is vooral de intensiteit en omvang ervan die de aandacht trekt. Voor vele literatuurliefhebbers zijn die mediaal geconditioneerde ontwikkelingen verontrustend, zodat ze aan de conditie van de hedendaagse literatuur in de categorieën 'crisis' of 'dood' gaan denken. Maar Bax constateert troostend dat de literatuur niet zal verdwijnen, want ze is simpelweg aan het evolueren door de stijgende dominantie van de massamediacultuur.

Uit het boek van Bax komt de nieuwe positie van schrijvers in de mediacultuur duidelijk aan het licht: ze moeten diverse strategieën ontwikkelen om vorm te geven aan hun literaire positie in de veranderende omstandigheden. Om succesvol te zijn moeten ze zich vooral als publieke figuur presenteren (de populairste varianten zijn literary celebrity of publieke intellectueel; 212). De schrijver die tegenwoordig zijn weg probeert te vinden in het labyrint van de massamedia houdt meer rekening met de verwachtingen van het publiek en doet actiever aan de promotie van zijn werk.

Bax merkt op dat de verschillen tussen diverse massamedia voor zijn onderzoek niet zo relevant zijn. Volgens hem bestaan er in die media (zonder betekenis, hoog of laag) in principe geen wezenlijke verschillen tussen literaire mediacontent voor doorsnee ontvangers en degene die meer geïnteresseerd zijn in literaire problematiek. Dit is wel een pragmatische aanpak, die het betoog overzichtelijker laat organiseren, zonder in te hoeven gaan op details die typisch zijn voor afzonderlijke media. Maar het is toch jammer dat de auteur zo makkelijk aan die reëel

9 Een van de cruciale kwesties voor de eenentwintigste-eeuwse literatuur; Bax onderschrijft hier de stelling van Bas Heijne uit zijn essay Echt zien. Literatuur in het mediatijdperk en wijst erop dat "de mediacultuur" over het algemeen een probleem heeft met het concept "fictie" (160). 
bestaande, media-specifieke verschillen voorbijgaat, want het zou een waardevolle aanvulling zijn geweest voor zijn onderzoek. Het weglaten ervan verarmt het beeld van de literatuur in de massamediacultuur tot op zekere hoogte, vlakt het af. Je kan je toch niet tot de analyse van het woord/het verbale beperken, als je de invloed van de massamedia analyseert; het beeld en/of het geluid kunnen ook een zekere rol spelen bij hoe de schrijvers en hun boeken bij de mediagebruikers overkomen. Het zou juist interessant zijn om te kijken hoe de schrijvers hun houding en boodschap aanpassen aan een specifiek medium. En hoe deze media, afhankelijk van hun specificiteit, boodschappen over literaire werken en schrijvers differentiëren. Vermoedelijk zou het beeld van de literatuur in tijden van toenemende mediatisering daardoor completer en getrouwer zijn.

Het boek van Bax is wel bedoeld voor lezer met enig cultureel kapitaal, niettemin is het makkelijk te begrijpen door iemand die niet zo veel afweet van de Nederlandse literatuurgeschiedenis of literaire theorieën in het algemeen; want in dit geval vormt het gebrek aan kennis van bijvoorbeeld veldtheorie geen belemmering om Bax' heldere betoog met gemak te kunnen volgen. Het is soepel geschreven, zonder onbegrijpelijk wetenschappelijk jargon dat zou afschrikken. Het verbaast niet dat De literatuur draait door positief ontvangen is door lezers en ook veel belangstelling kreeg in de media (als bewijs voor de stelling dat de massamedia zelfreflexief zijn en het graag over zichzelf hebben). Ook uit didactisch perspectief lijkt dit boek een must have, een interessante optie waarmee je effectief kan werken in de colleges moderne Nederlandse literatuur- en cultuurgeschiedenis, alsook literatuurwetenschap aan de universiteiten buiten Nederland en België.

Sander Bax, De literatuur draait door. De schrijver in het mediatijdperk, Prometheus, 2019, ISBN 978-90-446-4028-1, 352 pp.

\section{Bibliografie}

Loisen, Jan, en Stijn Joye, m.m.v. Hans Verstraeten. Communicatie \& media. Een inleiding tot communicatiewetenschappen. Onderzoek en theorie. Acco, 2016.

Ruyters, Jann. "Interview. Literatuurwetenschapper Sander Bas: Een uitgever zegt sneller u verkoopt wel erg weinig boeken". De Trouw, 23 februari 2019. https://www.trouw.nl/nieuws/literatuurwetenschapper-sander-bax-een-uitgever-zegt-sneller-u-verkoopt-wel-erg-weinig-boeken $\sim$ b7de 7356/?referrer=https\%3A\%2F\%2Fwww.google.com\%2F. Geraadpleegd 20 augustus 2021. 